\title{
Oxygen delivery systems for adults in Sub-Saharan Africa: A scoping review
}

Neelima Navuluri ${ }^{1,2}$, Maria

L Srour $^{3}$, Peter S Kussin ${ }^{1,2}$,

David M Murdoch ${ }^{1}$,

Neil R MacIntyre ${ }^{1}$,

Loretta G Que ${ }^{1}$, Nathan

M Thielman ${ }^{2,4}$, Eric D

McCollum $^{5}$

${ }^{1}$ Division of Pulmonary, Allergy, and Critical Care, Department of Medicine, Duke University School of Medicine, Durham, North Carolina, USA

2Duke Global Health Institute, Duke University, Durham, North Carolina, USA

${ }^{3}$ Division of Pulmonary, Allergy, and Critical Care, Department of Medicine, Indiana University School of Medicine, Indianapolis, Indiana, USA

${ }^{4}$ Division of Infectious Diseases, Department of Medicine, Duke University School of Medicine, Durham, North Carolina, USA ${ }^{5}$ Global Program in Respiratory Sciences, Eudowood Division of Pediatric Respiratory Sciences, Department of Pediatrics, Johns Hopkins School of Medicine, Baltimore, Maryland, USA

\section{Correspondence to:}

Neelima Navuluri, MD, MPH DUMC 102355

315 Hanes House Room 100

Durham, NC 27708

USA

Neelima.navuluri@duke.edu
Background Respiratory diseases are the leading cause of death and disability worldwide. Oxygen is an essential medicine used to treat hypoxemia from respiratory diseases. However, the availability and utilization of oxygen delivery systems for adults in sub-Saharan Africa is not well-described. We aim to identify and describe existing data around oxygen availability and provision for adults in sub-Saharan Africa, determine knowledge or research gaps, and make recommendations for future research and capacity building.

Methods We systematically searched four databases for articles on April 22, 2020, for variations of keywords related to oxygen with a focus on countries in sub-Saharan Africa. Inclusion criteria were studies that included adults and addressed hypoxemia assessment or outcome, oxygen delivery mechanisms, oxygen availability, oxygen provision infrastructure, and oxygen therapy and outcomes.

Results: 35 studies representing 22 countries met inclusion criteria. Availability of oxygen delivery systems ranged from $42 \%-94 \%$ between facilities, with wide variability in the consistency of availability. There was also wide reported prevalence of hypoxemia, with most studies focusing on specific populations. In facilities where oxygen is available, health care workers are ill-equipped to identify adult patients with hypoxemia, provide oxygen to those who need it, and titrate or discontinue oxygen appropriately. Oxygen concentrators were shown to be the most cost-effective delivery system in areas where power is readily available.

Conclusions There is a substantial need for building capacity for oxygen delivery throughout sub-Saharan Africa. Addressing this critical issue will require innovation and a multi-faceted approach of developing infrastructure, better equipping facilities, and health care worker training.

Respiratory diseases are the leading cause of death and disability worldwide. Oxygen is an essential, life-saving medical therapy that has been used to treat respiratory disease since the late 1800s [1,2]. It is used to treat both acute and chronic conditions which result in hypoxemia, which is an abnormally low concentration of oxygen in the blood. For adult patients with chronic hypoxemia from primary lung disease or heart failure, long term oxygen therapy is a well-established cornerstone of management, improving survival and quality of life $[3,4]$.

Oxygen has been listed as one of the World Health Organization's (WHO) Essential Medicines since the first online edition in 2002, but only for anesthesia. Hypoxemia was added as an indication only recently in 2017 [5,6]. The simplest way to identify 
patients who are hypoxemic is by measuring oxygen saturation of the blood with a pulse oximeter, which uses infrared light refraction to non-invasively measure the percentage of oxygen in red blood cells. Supplemental oxygen can be provided via cylinders (gas or liquid), oxygen concentrators, or larger oxygen plants, each of which have unique advantages and disadvantages depending on environment and resource infrastructure. WHO guidelines on the clinical use of oxygen in children and technical specifications for oxygen equipment are available $[7,8]$. These highlight the need for pulse oximetry, appropriate clinical evaluation and management of underlying etiology, and basic administration standards. They notably do not specify guidelines for adults.

Despite widespread recognition of the importance of oxygen therapy for treatment of hypoxemia, its use and implementation remain inadequate in much of the world. Specifically, there is limited data about hypoxemia recognition and oxygen provision across sub-Saharan Africa (SSA), with most existing data focusing on acute oxygen needs among children and neonates. In order to design interventions and implementation efforts, a better understanding of the existing ecosystem is required, especially as it relates to adult populations.

In this scoping review, we aimed to identify and describe existing data around oxygen availability and provision for adults in SSA in order to determine areas of research or knowledge gaps on this topic and make recommendations for future research and capacity building. We hypothesized that the literature on adults would be limited as compared to pediatric populations, that what did exist would highlight the lack of availability, usage, and utilization of oxygen delivery systems for adults, and would identify key barriers of oxygen usage and opportunities for future research and capacity building.

\section{METHODS}

We used the Arksey and O'Malley methodological framework, along with Levac's recommendations for each stage of the framework, to perform a scoping review of what is known about oxygen delivery systems in SSA [9,10]. A review framework was prepared to develop the overall study protocol including identifying the research question, searching for relevant studies, selecting studies, charting the data, and collating, summarizing, and reporting the results.

\section{Identifying the research question}

The central research question of this scoping review is: what is known in existing literature about oxygen provision to adult patients with hypoxemia in SSA, what knowledge and research gaps exist, and what recommendations for future research and capacity building can be made?

\section{Search strategy and selection criteria}

We performed a systematic search of online databases (PubMed, EMBASE, African Index Medicus, and Web of Science) on April 22, 2020, with the assistance of a medical librarian. All articles from 1970-2020 were included. The review was conducted applying the search words "Africa," "oxygen inhalation therapy," "oxygen/ supply and distribution," "oxygen/therapeutic use," and "oxygen" with "domiciliary," "home," "therapy," "concentrator," "tank," "cylinder," "delivery," "distribution," or "supply," as the Medical Subject Heading (MeSH) headings (Table 1).We included any study which included adults and addressed any of the following areas: hypoxemia assessment or outcome, oxygen delivery mechanisms, oxygen availability, oxygen provision infrastructure, and oxygen therapy and outcomes. Basic science studies, case reports, studies focusing only on neonates, children, or fetal outcomes among pregnant women, hyperbaric oxygen therapy, mechanical ventilation or oxygen in the setting of anesthesia, studies based wholly outside of SSA, and those for which no full article could be found were excluded. One investigator reviewed the titles and abstract of the studies for inclusion and an additional investigator assisted in full-text review for final inclusion. These two investigators also charted, collated, and summarized the data.

\section{Charting the data, summarizing and reporting}

We used a data collection form adapted from the Cochrane Effective Practice and Organization of Care group [11]. For each included study, we extracted data on study design, country or region of study, sample size, oxygen delivery device and patient interface, power source, population setting, facility, measured outcomes, and interventions where available. 
Table 1. Search terms

\section{SET TERMS}

"Africa"[Mesh]. OR Africa[all fields]. OR Algeria[all fields]. OR Angola[all fields]. OR Benin[all fields]. OR Botswana[all fields]. OR "Burkina Faso"[all fields]. OR Burundi[all fields]. OR "Cabo Verde"[all fields]. OR "Cape Verde"[all fields]. OR "Central African"[all fields]. OR Chad[all fields]. OR Comoros[all fields]. OR Congo[all fields]. OR "Cote d Ivoire"[all fields]. OR "Cote divoire"[all fields]. OR Congo[all fields]. OR Djibouti[all fields]. OR Egypt[all fields]. OR" Guinea"[all fields]. OR Eritrea[all fields]. OR Ethiopia[all fields]. OR Gabon[all fields]. OR Gambia[all fields]. OR Ghana[all fields].

$\# 1$ OR Guinea[all fields]. OR Kenya[all fields]. OR Lesotho[all fields]. OR Liberia[all fields]. OR Libya[all fields]. OR Libyan[all fields]. OR Madagascar[all fields]. OR Malawi[all fields]. OR Mali[all fields]. OR Mauritania[all fields]. OR Mayotte[all fields]. OR Morocco[all fields]. OR Mozambique[all fields]. OR Namibia[all fields]. OR Niger[all fields]. OR Nigeria[all fields]. OR Rwanda[all fields]. OR Sahel[all fields]. OR "Sao Tome and Principe"[all fields]. OR Senegal[all fields]. OR "Sierra Leone"[all fields]. OR Somalia[all fields]. OR "South Africa"[all fields]. OR "South Sudan"[all fields]. OR Sudan[all fields]. OR Swaziland[all fields]. OR Tanzania[all fields]. OR Togo[all fields]. OR Tunisia[all fields]. OR Uganda[all fields]. OR Sahara[all fields]. OR Zambia[all fields]. OR Zimbabwe[all fields].

"Oxygen Inhalation Therapy"[Mesh]. OR "Oxygen/supply and distribution"[Mesh:NoExp]. OR "Oxygen/therapeutic use"[Mesh:NoExp]. OR (oxygen-

\#2 [tiab]. AND (domiciliary[tiab]. OR home[tiab]. OR therapy[tiab]. OR delivery[tiab]. OR distribution[tiab]. OR supply[tiab]. OR concentrator*[tiab]. OR cylinder*[tiab]. OR tank*[tiab].))

\#3 \#1 AND \#2

(randomized controlled trial[pt]. OR controlled clinical trial[pt]. OR randomized[tiab]. OR randomised[tiab]. OR randomization[tiab]. OR randomisation[tiab]. OR placebo[tiab]. OR randomly[tiab]. OR trial[tiab]. OR study[tiab]. OR groups[tiab]. OR Clinical trial[pt]. OR "clinical trial”[tiab]. OR "clinical trials"[tiab]. OR "evaluation studies"[Publication Type]. OR "evaluation studies as topic"[MeSH Terms]. OR "evaluation study"[tiab]. OR evaluation studies[tiab]. OR "intervention study"[tiab]. OR "intervention studies"[tiab]. OR "case-control studies"[MeSH Terms]. OR "case-control”"[tiab].

\#4 OR "cohort studies"[MeSH Terms]. OR cohort[tiab]. OR "longitudinal studies"[MeSH Terms]. OR "longitudinal”[tiab]. OR longitudinally[tiab]. OR "prospective"[tiab]. OR prospectively[tiab]. OR "retrospective studies"[MeSH Terms]. OR "retrospective"[tiab]. OR observational[tiab]. OR "follow up"[tiab]. OR "comparative study"[Publication Type]. OR "comparative study"[tiab]. OR systematic[subset]. OR "meta-analysis"[Publication Type]. OR "meta-analysis as topic"[MeSH Terms]. OR "meta-analysis"[tiab]. OR "meta-analyses"[tiab].) NOT (Editorial[ptyp]. OR Letter[ptyp]. OR Case Reports[ptyp]. OR Comment[ptyp].) NOT (animals[mh]. NOT humans[mh].)

\#5 \#4 AND \#3

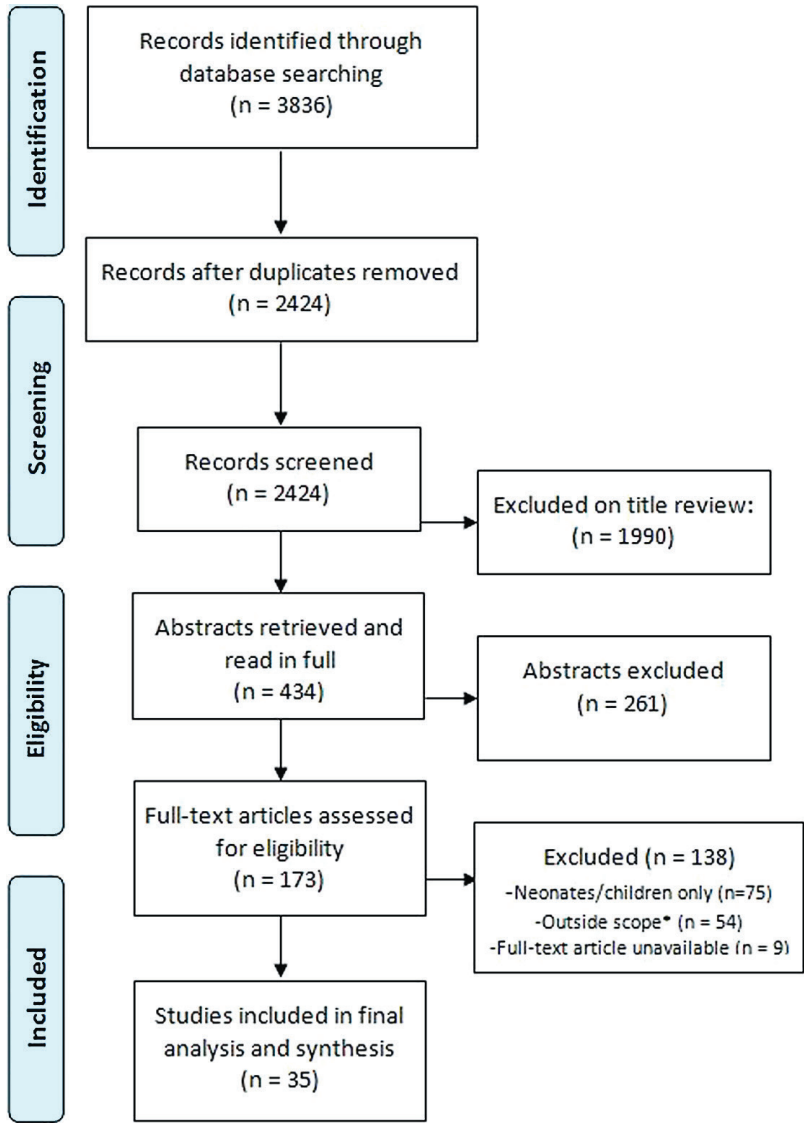

Figure 1. PRISMA flowchart detailing study selection. * Did not describe current state of oxygen availability, provision and/or oxygen delivery mechanisms or were studies based entirely outside of SSA.
The data were recorded in a series of tables, enabling repeated exploring of themes. After an iterative process of data extraction, recording, and thematic review, we aggregated studies into major themes and then collated the data to help describe the existing knowledge around oxygen availability and provision and analyze for key knowledge and research gaps.

\section{Patient and public involvement}

No patients nor members of the public were involved in the review.

\section{RESULTS}

\section{Description of studies}

Of 2424 papers screened, 173 full-text articles were assessed for eligibility (Figure 1). We ultimately included 35 articles describing 34 different studies.

A total of 22 SSA countries were represented in the studies (Figure 2), with 5 studies including data from multiple countries. Studies were published between 1995 and 2020 with data collection ranging from 1995 to 2017.

We identified three key themes among these articles, each with multiple sub-themes about the use of oxygen therapy in SSA (Table 2 and Table 3). These themes are oxygen availability, infrastructure, and usage ( $\mathrm{n}=26)$, hypoxia assessment and clinical understanding and management $(\mathrm{n}=24)$, and cost and cost-effectiveness $(n=4)$, and each are elaborated upon below. Eight articles contained two themes. 


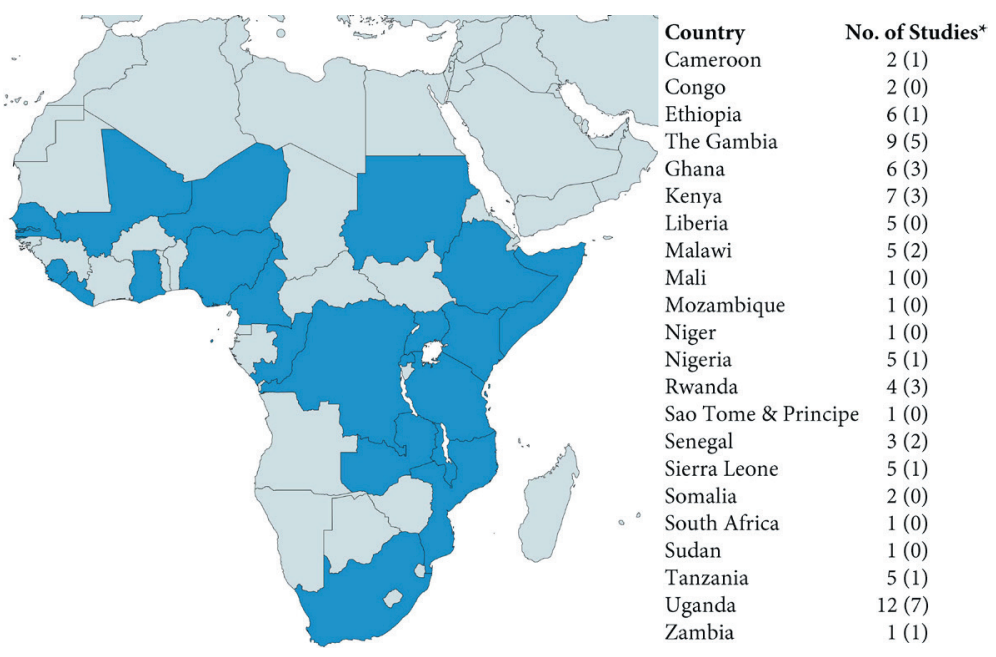

Figure 2. Countries represented in available studies. ${ }^{*}$ First number indicates number studies in total, including studies which included multiple sites. Number in parenthesis indicates number of single-site studies.

\section{Oxygen availability, infrastructure, and usage}

Several of the reviewed studies used surveys to assess the available equipment in health care settings throughout SSA. These surveys showed a lack of basic equipment such as pulse oximeters and oxygen delivery systems, eg, cylinders or concentrators. Availability of oxygen delivery systems ranged from $42 \%-94 \%$ between facilities, with wide variability in the consistency of availability $[13-15,18,20,22,24,25,28,30,33]$. For example, the highest reported availability was in a study of private and public facilities in Uganda which showed that 15 of 16 facilities had access to oxygen at least half of the time. However, six of those hospitals lacked access to oxygen more than $25 \%$ of the time and one hospital never had access to oxygen [14]. The availability of pulse oximetry was significantly more limited, ranging from $0 \%-64 \%$ of facilities assessed $[20,27,33]$. This suggests that while facilities may have oxygen available, their ability to accurately identify patients who may need oxygen and titrate the amount delivered appropriately is limited. These limitations are especially true for public facilities and those providing lower tiers of care $[13,14,28]$.

Three studies assessed infrastructure in low- and middle-income countries (LMICs) across the world; data specific to SSA was extracted from these studies and demonstrate similar findings $[26,27,29]$. These studies were focused on surgery and anesthesia capacity, but included assessments of the facilities at large and thus were included in this review. Kushner et al found $46 \%$ of facilities across eight LMICs (four of which were in SSA - Tanzania, Sierra Leone, Liberia, and The Gambia) never had oxygen available, 33\% had it sometimes available, and $21 \%$ had it always available [26]. Likewise, a cross-sectional survey assessing cesarean-section delivery capacity across 26 LMICs (13 in SSA - Congo, Ethiopia, The Gambia, Ghana, Kenya, Liberia, Malawi, Niger, Nigeria, Sierra Leone, Somalia, Uganda and Tanzania) found that 21\% of facilities performing cesareans reported not having a reliable supply of oxygen and that $26 \%$ of those referring out did not have any supply [29]. An additional study which compared in-hospital mortality among inpatients between an Ugandan hospital and Canadian hospital noted that there was only one oxygen concentrator available in a large regional hospital in Uganda [31].

Issues in oxygen availability extend beyond the availability of the oxygen delivery systems themselves. Delivering oxygen from a cylinder or concentrator to a patient requires basic equipment such as tubing to connect the system to a patient delivery device such as a face mask or nasal prongs. A notable multi-SSA country assessment demonstrated that not only do less than half of the facilities report access to an oxygen source, but that only 34.3\% had at least one face mask and tube set available [15]. Furthermore, for oxygen concentrators to function, electricity must be readily available. This is a major issue for many facilities, with only 35\%-68\% having electricity fully available $[15,27,32]$. Backup power generators are often utilized in areas where consistent electricity may be lacking, but many facilities do not have access to functioning generators, relying instead on solar power $[15,27,30,32]$. Even in places where oxygen concentrators and power are available, many do not function properly or provide the indicated amount of oxygen $[21,23]$.

There are promising strides in systematically determining the best approach to providing oxygen and developing innovative oxygen delivery and storage systems in under-resourced areas. Oxygen concentrators have been demonstrated to be much more cost-effective than cylinders for oxygen delivery without sacrificing medical benefit [24]. Replacing cylinders with oxygen concentrators and addressing the issue of reliable power by installing an uninterrupted power supply has been shown to be easy to maintain and cost-effective [17]. Oxygen storage systems or reservoirs, which store oxygen in low-pressure devices, have been effective in maintaining flow regardless of interruption in power supply for up to 30 days and reducing the number of oxygen outage events $[19,34]$. While there are limitations to large-scale implementation of these types of reservoirs including clinical trial data, space requirements, and significant need for personnel education, innovations such as these will be imperative in overcoming the "energy poverty" that challenges SSA [32]. 
Table 2. Oxygen availability, infrastructure, and usage and cost and cost-effectiveness

\begin{tabular}{lll}
$\begin{array}{l}\text { AUTHOR, } \\
\text { YEAR }\end{array}$ & COUNTRY & $\begin{array}{l}\text { FACILITY TYPE AND } \\
\text { SETTING }\end{array}$ \\
Adipa, & Gorle Bu Teaching \\
$2015[12]$ & & $\begin{array}{l}\text { Kospital - Emergency } \\
\text { Department and ICU }\end{array}$ \\
\hline
\end{tabular}

\section{DATA SOURCE}

Face to face interviews

with health care workers (HCWs)

Surgical Assessment

Tool (SAT) developed by

Albutt,

2018 [13] Uganda

17 public hospitals the Program in Global

Surgery and Social Change and the WHO

\section{WHO Tool for}

Situational Analysis to

Assess Emergency and

Essential Surgical Care

(TSAAEESC)

\begin{tabular}{lll}
\hline & Ethiopia, The Gambia, & 231 health centers and \\
Ghana, Kenya, Liberia, & hospitals; 23\% private, \\
Belle, & Malawi, Mali, Nigeria, & $38 \%$ primary care, 31\% $\quad$ WHO TSAAEESC \\
$2010[15] \quad \begin{array}{l}\text { Sierra Leone, Sao Tome } \\
\text { \& Principe, Tanzania, }\end{array}$ & district or regional and \\
& Uganda
\end{tabular}

Bradley,

2015* [16] The Gambia

Biomedical Engineering

Department at the

Medical Research

Council Unit
Retrospective analysis of electronic maintenance records for 27 oxygen concentrators

\section{KEY FINDINGS}

Oxygen was readily available via cylinders, but cumbersome tanks often had to be moved across wards for patient access.

Oxygen was available more than half the time at $68.8 \%$ of facilities while continuous pulse oximetry was always available in the operating room in only $62.5 \%$ of hospitals.

93.8\% of hospitals had oxygen but only $37.5 \%$ of had it for more than $25 \%$ of the time.

$43.8 \%$ of hospitals had a consistently available oxygen source; $31.4 \%$ had intermittent availability. Oxygen cylinders, concentrators and face masks and tubing were readily available in less than 35\% of hospitals. Electricity and generator supply were similarly sporadic.

The majority of concentrator faults were repairable for less than US $\$ 10$, with the average costs of the most common repairs - filter and check valve replacements - US $\$ 4.53$ and US $\$ 6.80$ respectively. Median cost of repairs was US $\$ 9.44$ with a maximum of US\$573. The authors predict a seven year lifespan for concentrators in low resource settings with a US $\$ 15$ per machine-year of service repair cost.

42 bed hospital in Bradley,
$2016^{*}[17]$$\quad$ The Gambia the Medical Research Council Unit

Assessment of oxygen concentrator function and user feedback

The hospital system saved $51 \%$ of oxygen costs by using concentrators which amounted to US $\$ 45000$ over the course of $8 \mathrm{y}$.

Continuous oxygen supply was not available in 33\% of facilities and 59\% had interrupted electricity. As part of their Safe Surgery initiative, 2 oxygen plants were built at referral hospitals.

\begin{tabular}{|c|c|c|c|}
\hline $\begin{array}{l}\text { Burssa, } \\
2017[18]\end{array}$ & Ethiopia & $\begin{array}{l}29 \text { facilities throughout } \\
\text { Ethiopia }\end{array}$ & $\begin{array}{l}\text { Ministry of Health } \\
\text { Assessment }\end{array}$ \\
\hline
\end{tabular}

\begin{tabular}{lll}
\hline Calderon, Uganda & $\begin{array}{l}\text { Jinja Regional Referral } \\
\text { Hospital }\end{array}$ & Prototype Assessment \\
\hline
\end{tabular}

Desalu,
$2011[20] \quad$ Nigeria
A storage system was able to delive oxygen in $56 \%$ of power outage minutes and cover over $99 \%$ of power outage events. In the studied tertiary care centers, $52.9 \%$ reported having a standard oxygen delivery system. Under $40 \%$ had pulse oximeters.

Evans,
$2012[21] \quad$ Malawi

hospital in Southern
Malawi

Hill,
2009 [22] The Gambia

12 health facilities -5
government referral hospitals, 7 health centers

Queen Elizabeth Central Hospital (QECH) - 1200 Cross-sectional study of adult medical inpatients and oxygen provision over $24 \mathrm{~h}$
8concentrators were present, but only 4 functioned appropriately. Three had oxygen flow rates $<60 \%$ of indicated; 1 did not function at all.

Royal Victoria Teaching

$\begin{array}{lll}\text { Howie, } & \text { The Gambia } & \text { Royal Victoria Teaching } \\ \text { 2008 [23] } & \text { Hospital (tertiary referral Interviews with HCWs } \\ \text { center) }\end{array}$
Howie,
$2009^{*}[24]$ The Gambia 11 public hospitals

Standardized WHO
questionnaire

6 of the 12 facilities surveyed had available oxygen supplies (cylinders and concentrators). The government central referral hospitals generally had good reliability of supply whereas large health centers did not.

Oxygen concentrators were donated from North America but required a different electrical frequency so were difficult to use. Very little training was given to providers and eventually the supply of concentrators went unused. Concentrators have significant advantage compared to cylinders where power is reliable. In other settings $\begin{array}{ll}\text { framework } & \text { cylinders preferred if transport is feasible. Cylinder costs } \\ \text { are influenced by leakage whereas concentrator costs are }\end{array}$ affected by cost of power. Only 2 of 12 facilities in Gambia were suitable for concentrators over cylinders. 
Table 2. Continued

\begin{tabular}{|c|c|}
\hline $\begin{array}{l}\text { AUTHOR, } \\
\text { YEAR }\end{array}$ & COUNTRY \\
\hline
\end{tabular}

\section{Kouo-}

Ngamby,

2015 [25] SETTING

12 public hospitals

WHO TSAAEESC

Kushner, Tanzania, Sierra Leone, 132 district hospitals in

2010 [26] Liberia, The Gambia 30 LMICs

WHO TSAAEESC
8 of the 12 hospitals had oxygen cylinder supply, but only 4 of the 12 had reliable oxygen concentrators. The greatest equipment needs were demonstrated in facilities providing lower tiers of care.

No country reported $100 \%$ of facilities having continuous water, electricity and oxygen supplies. Oxygen was never available in $46 \%$ of facilities.

Approximately $80 \%$ of hospitals had a reliable oxygen source in the operating theater (OT) while 59\% had pulse oximeters in each OT and 33\% had them in surgical recovery rooms. Many of the hospitals surveyed reported power outages or interruptions.

2014 [27] Rwanda, Uganda 78 district hospitals WHO TSAAEESC
23 health facilities of Facility-based survey various care levels; all to assess WHO-

Nyarko,

all funding from the
Ghanaian government

Congo, Ethiopia,

The Gambia, Ghana,

Ologunde, Kenya, Liberia, Malawi,

2014 [29] Niger, Nigeria, Sierra

Leone, Somalia,

Uganda, Tanzania
Package of Essential

Noncommunicable

Disease Interventions 2016 [28] Ghana

719 health facilities

WHO TSAAEESC
None of the community-based health care facilities had functional oxygen cylinders or pulse oximeters while district and regional hospitals all did. Access to medications and medical equipment improved with increased levels of care.
Oxygen was available in $73.3 \%$ of the facilities surveyed. At facilities that offer cesarean delivery, $78 \%$ had access to oxygen whereas only $21 \%$ of facilities that did not offer the procedure had available oxygen. The survey did not distinguish between cylinders and concentrators.

Of 11 facilities surveyed, $82 \%$ had at least one cylinder and at least one concentrator. A back-up generator was available at $64 \%$ of facilities. The study also found a high case fatality rate in hypoxemic patients with an upward trend in mortality in those who experienced interruptions in therapeutic oxygen supply.

This study compared prospective data from Uganda to retrospective data from Canada to compare in-hospital mortality in patients with similar admission characteristics. It noted that there was only 1 oxygen concentrator at the hospital in Uganda.

$52 \%$ of health care facilities do not have access to regular uninterrupted electricity. Most of these facilities are

bed private not-for-profit Prospective data regional hospital

Opio, 2014 [31] Uganda
Ouedraogo, 2018 [32] Senegal
All formal sector health facilities in the country
Senegal Service Provision Assessments using a generator or solar supply. $11 \%$ of facilities with oxygen concentrators do not have the electricity to power them.

Of the facilities surveyed, which together serve $46 \%$ of the Tanzanian population, $42 \%$ had consistent access to oxygen delivery, most of which used concentrators. Only $37.5 \%$ had reliable running water and electricity. A total of 6 functional pulse oximeters were located across all 48 facilities.

Penoyar, Tanzania 48 public hospitals $\quad$ WHO TSAAEESC
2012 [33]

A low-pressure oxygen storage system designed by a team in Australia was able to provide continuous oxygen supply to a simulated patient without interruption for 30 $\mathrm{d}$. The estimated cost of the system was US $\$ 460$. The main drawback noted was the large amount of space the system occupies

Of 199 patients admitted to the hospital during the study period, 62 met SIRS criteria and were enrolled in the

Rudd, 2017 [35] Uganda
Bwindi Community

Hospital - a private, 112-bed, rural hospital
Prospective observational single cohort study study. In the adult population, $44 \%$ of patients hypoxic to $<94 \% \mathrm{O}_{2}$ were treated with oxygen therapy; $100 \%$ of those hypoxic to $<90 \%$ were. Only 1 of the patients studied died in the hospital while $92 \%$ of patients went home in improved condition.

*Article also addresses cost and/or cost-effectiveness. 
Table 3. Hypoxemia assessment and clinical understanding and management articles

\begin{tabular}{|c|c|c|c|c|}
\hline $\begin{array}{l}\text { AUTHOR, } \\
\text { YEAR }\end{array}$ & COUNTRY & $\begin{array}{l}\text { FACILITY TYPE AND } \\
\text { SETTING }\end{array}$ & DATA SOURCE & KEY FINDINGS \\
\hline $\begin{array}{l}\text { Adipa, } \\
2015 \text { [12] }\end{array}$ & Ghana & $\begin{array}{l}\text { Surgical Medical } \\
\text { Emergency and } \\
\text { Cardiothoracic Intensive } \\
\text { Care Unit at Korle Bu }\end{array}$ & $\begin{array}{l}\text { Face to face interviews } \\
\text { with health care } \\
\text { workers (HCWs) }\end{array}$ & $\begin{array}{l}\text { Nursing education on oxygen therapy was inadequate and a } \\
\text { knowledge gap exists. Nurses require more training in assessing } \\
\text { oxygen needs and administering therapy appropriately. }\end{array}$ \\
\hline
\end{tabular}

\section{Queen Elizabeth}

Central Hospital

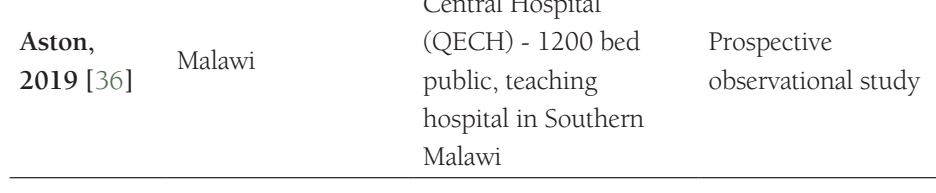

\begin{tabular}{|c|c|c|}
\hline $\begin{array}{l}\text { Dickson, } \\
2018 \text { [37] }\end{array}$ & Sierra Leone & $\begin{array}{l}\text { UK military Ebola } \\
\text { treatment center }\end{array}$ \\
\hline
\end{tabular}

\begin{tabular}{lll}
\hline $\begin{array}{l}\text { Evans, } \\
2012[21]\end{array}$ & Malawi & \\
& & \\
\hline Foran, & Zambia & Kapiri District Hospital \\
$2010[38]$ & & -60 bed government \\
& & run district hospital \\
\hline
\end{tabular}
Retrospective analysis of clinical charts

Cross-sectional study of adult medical inpatients and oxygen provision over $24 \mathrm{~h}$
Hypoxemia ( $\mathrm{SpO}_{2}<90 \%$ ) was strongly associated with 30-d mortality among 459 patients hospitalized with communityacquired pneumonia (CAP). Authors comment that oxygen provision is an obvious strategy to improve CAP outcomes.

The lowest oxygen saturations recorded in fatal cases were lower

than cases that survived. Oxygen was administered to $18 / 41$ Ebola patients via concentrators and 16 of those 18 patients died.

Cross-sectional study of 109 adults were assessed, of whom 9\% were hypoxemic

inpatients $\quad\left(\mathrm{SpO}_{2}<90 \%\right)$

14 of 144 (9\%) patients studied had $\mathrm{SpO}_{2}<90 \%$ and met criteria for oxygen supplementation, but only $4(29 \%)$ received $\mathrm{O}_{2}$ therapy.

$25 \%$ of doctors surveyed were demonstrated to manage asthma

$\begin{array}{lll}\text { Hesse, } & \text { Korle-Bu Teaching } & \text { Cross-sectional survey } \\ 1995[39] & \text { Hospital } & \text { of first-year doctors }\end{array}$
appropriately. $28 \%$ of doctors used oxygen for mild to moderate asthma, and $74 \%$ used it for severe asthma. Some doctors were not aware there was some degree of hypoxemia even with mild asthma

\begin{tabular}{|c|c|c|c|}
\hline $\begin{array}{l}\text { Kabeza, } \\
2012[40]\end{array}$ & Rwanda & $\begin{array}{l}\text { Kigali University } \\
\text { Teaching Hospital }\end{array}$ & $\begin{array}{l}\text { Prospective } \\
\text { observational study of } \\
125 \text { patients undergoing } \\
\text { abdominal surgery }\end{array}$ \\
\hline
\end{tabular}

$24 \%$ of patients transferred to PACU were hypoxemic

$\left(\mathrm{SpO}_{2}<90 \%\right)$ and of those, $27 \%$ were transferred without

supplemental $\mathrm{O}_{2} .50 \%$ of patients were hypoxemic at least once during the study period.

This study assessed the compliance with traumatic brain injury

Thika Level 5 hospital

Mwita, Kenya
2016 [41] in Kiambu County in Central Kenya
Retrospective clinical audit (TBI) management criteria, one of which is oxygen therapy. Only $21 \%$ of patients $13 y$ rs or older (mean age 29.8) with TBI were administered oxygen as indicated. The authors speculate that lack of availability is a significant factor.

This study compared prospective data from Uganda to

Kitovu Hospital - 220

Opio,
$2014[31] \quad$ Uganda bed private not-for-

profit regional hospital
Prospective data retrospective data from Canada to compare in-hospital mortality in patients with similar admission characteristics. It noted 3.9\% of patients were on supplemental oxygen vs $31.2 \%$ of patients in Canada.

Of 199 patients admitted to the hospital during the study period, 62 met SIRS criteria and were enrolled in the study. In the adult population, $44 \%$ of patients hypoxic to $<94 \% \mathrm{O}_{2}$ were treated with oxygen therapy; $100 \%$ of those hypoxic to $<90 \%$ were Only one of the patients studied died in the hospital while $92 \%$ of patients went home in improved condition.
Prospective

observational single

cohort study
Rudd,
2017 [35] Uganda

Bwindi Community

Hospital - a private,

112-bed, rural hospital
Senegal, Nigeria,

Cameroon, Ethiopia,

Sani, 2017 [42] Kenya, South Africa, 12 cardiology centers Mozambique, Uganda, Sudan

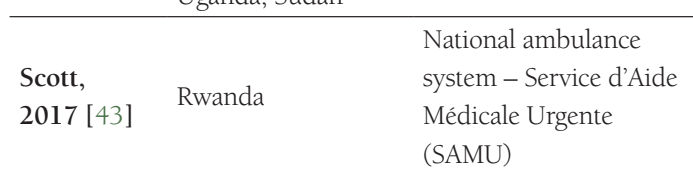

Prospective multicenter observational survey

Prospective Quality Improvement (QI) Study
Assessed changes in signs and symptoms of heart failure over the course of hospitalization. Oxygen saturation was predictive of death or heart failure exacerbation through day 60 .
Implemented monthly presentations to the ambulance service and assessed quality metrics including supplementary oxygen for hypoxia. Use of supplemental oxygen improved from $75 \%$ preintervention to $92 \%$ post-intervention. 
Table 3. Continued

\begin{tabular}{|c|c|c|c|c|}
\hline $\begin{array}{l}\text { AUTHOR, } \\
\text { YEAR }\end{array}$ & COUNTRY & $\begin{array}{l}\text { FACILITY TYPE AND } \\
\text { SETTING }\end{array}$ & DATA SOURCE & KEY FINDINGS \\
\hline $\begin{array}{l}\text { Sutherland, } \\
2019 \text { [44] }\end{array}$ & Rwanda & $\begin{array}{l}\text { University Teaching } \\
\text { Hospital of Kigali } \\
\text { Emergency Department }\end{array}$ & QI Study & $\begin{array}{l}12.1 \% \text { of } 1765 \text { patients screened were hypoxemic. } 81.3 \% \text { of } \\
\text { patients were either under- or over-treated with oxygen. An } \\
\text { intervention that provided didactics and pulse oximetry to } \\
\text { providers helped improve clinician's knowledge scores, oxygen } \\
\text { provision and titration, and decreased tank use per day. Results } \\
\text { persistent at } 4 \text { weeks and } 12 \text { weeks. }\end{array}$ \\
\hline $\begin{array}{l}\text { Toure, } \\
2000[45]\end{array}$ & Senegal & $\begin{array}{l}\text { Dakar University } \\
\text { Hospital Center } \\
\text { Cardiology Department }\end{array}$ & $\begin{array}{l}\text { Retrospective Cross } \\
\text { Sectional }\end{array}$ & 30 of $34(88.8 \%)$ patients with cor pulmonale were hypoxemic. \\
\hline $\begin{array}{l}\text { Worodria, } \\
2018 \text { [46] }\end{array}$ & Uganda & Mulago Hospital & $\begin{array}{l}\text { Secondary analysis } \\
\text { of established cohort } \\
\text { of adult patients } \\
\text { hospitalized with } \\
\text { lower respiratory tract } \\
\text { infection }\end{array}$ & $\begin{array}{l}10.6 \% \text { of } 1887 \text { patients had severe hypoxemia }\left(\mathrm{SpO}_{2}<90 \%\right) \text { on } \\
\text { RA; hypoxemia was associated with in-hospital and post-hospital } \\
\text { mortality (adjusted OR of } 2.75 \text { and } 2.09 \text { respectively). }\end{array}$ \\
\hline
\end{tabular}

There are also issues in the way in which concentrators are provided. In 2000, a group of North American philanthropists donated more than 20 oxygen concentrators to the Royal Victoria Teaching Hospital, The Gambia's tertiary referral hospital. However, within weeks, none of the concentrators remained in use. A techni$\mathrm{cal}$ and qualitative assessment found that the donation process was flawed, the receiving personnel were not adequately trained in the use or maintenance of the machines, and the electrical frequency of the devices was different than the hospital's electrical supply and would never have worked, even with a transformer [23].

\section{Hypoxemia assessment and clinical understanding and management}

An understanding of the prevalence of hypoxemia is critical in ensuring that the supply of oxygen in areas where it may be available is truly meeting the demand. Furthermore, medical staff and providers should have a clear understanding of the indications of oxygen, the appropriate route and titration of oxygen therapy, and when to discontinue it. Ten studies addressed the question of prevalence of hypoxemia and demonstrated variability in the assessment of hypoxemia across institutions and countries, as well as the lack of generalized data with most focusing on very specific populations. An additional five provided insight on the understanding of oxygen therapy and management of hypoxemic patients in SSA.

Overall prevalence of hypoxemia, as measured by handheld pulse oximetry among adults in a district hospital in Zambia was 9\%, among adult inpatients in Malawi was 9\%, and among adults in the emergency department at a teaching hospital in Rwanda was $12.1 \%$ [21,38,44]. The study comparing a Ugandan hospital and Canadian hospital assessed oxygen saturation but did not remove oxygen supplementation at the time of measurement, making their values difficult to interpret [31].

Five studies assessed hypoxemia among specific populations, ranging from those with cor pulmonale to sepsis to Ebola Virus Disease. The heterogeneity in patient populations makes it difficult to discern the overall need in various settings, but prevalence ranged from 11\%-89\% [35,37,40,45,46]. Several of these studies demonstrated high mortality among those with hypoxemia and an additional two studies focused specifically on hypoxemia as a risk factor for mortality $[36,42]$. For example, among hospitalized patients who presented with lower respiratory tract infection and cough at Mulago Hospital in Uganda, 10.6\% had an oxygen saturation of $<90 \%$, and hypoxemia was associated with both in-hospital and two-month mortality [46]. Among patients with Ebola Virus Disease in West Africa, 18 of 41 (44\%) patients required and received supplemental oxygen via concentrators, and 16 of 18 (89\%) died [37]. The highest prevalence was seen among 34 patients with chronic cor pulmonale in Senegal where $88.8 \%$ were hypoxemic [45]. Unsurprisingly, oxygen saturation on admission was found to be a predictor of mortality among patients with heart failure across sub-Saharan Africa,[42] adults admitted for community-acquired pneumonia in Malawi, [36] and associated with mortality among hospitalized patients managed for chronic obstructive pulmonary disease (COPD) in Nigeria [47].

In order to ensure understanding and management of hypoxemia, there is a critical need for equipment such as pulse oximetry, more training in identifying and responding to hypoxemia with oxygen, and standardized 
protocols to guide initiation, titration, and discontinuation of oxygen therapy. Even when hypoxemia was identified, oxygen was not always provided or used appropriately with only 27\%-29\% of patients with hypoxemia receiving oxygen in two different studies [21,40]. Similarly, compliance with oxygen therapy in traumatic brain injury patients was found to be "dismal" [41]. An assessment of first year doctors in Ghana found that $28 \%$ prescribed oxygen for mild to moderate asthma and $74 \%$ for severe asthma, with many unaware that there was some degree of hypoxemia even with mild asthma [39]. A qualitative assessment in Ghana found nurses had a lack of knowledge about the appropriate amount of oxygen to provide and when to discontinue oxygen, and they strongly desired standardized protocols [12].

Efforts are being made to improve these metrics as highlighted by a quality improvement project in which daily team meetings and monthly feedback sessions improved supplemental oxygen administration for hypoxia from $75 \%$ to $92 \%$ among pre-hospital care providers in Rwanda [43].

\section{Cost and cost-effectiveness}

Four articles addressed the cost and cost-effectiveness of various oxygen delivery mechanisms, three of which were based on projects in The Gambia $[16,17,24,34]$. Oxygen concentrator systems with an uninterruptable power supply could save up to $51 \%$ of oxygen supply costs as compared to cylinders, amounting to a total cost of only US $\$ 45000$ over the course of eight years [17]. However, the cost-advantage only applies in areas where power is reliable, which as previously described is a major barrier for many facilities [24]. Fortunately, innovations such as the low-pressure oxygen storage system tested in Uganda cost as little as US\$460 and generate little extra electricity costs [34]. Concentrators can also be properly maintained in resource-limited settings with most concentrator faults repairable for less than US\$10 on average [16].

\section{DISCUSSION}

Our scoping review of available studies reveals that there is a widespread lack of access to and infrastructure for oxygen delivery systems across SSA, and that while this is a relatively understudied area with limited literature, there are several key opportunities to address this issue. It is noted that the majority of studies on oxygen therapy in SSA focus on neonates and children, which is understandable given the high mortality from pneumonia for children under five years. However, respiratory diseases remain the leading cause of death and disability in the world, with diseases such as COPD, asthma, pulmonary hypertension, lung cancer, and tuberculosis killing millions of adults annually. Although efforts are being made to address prevention of these diseases, huge strides are needed to reduce the burden of these diseases and resulting mortality among adults [1]. Availability of and access to oxygen therapy to treat patients with acute or chronic hypoxemia from these diseases is paramount.

Our review of the available studies involving adults demonstrates a dire lack of access to oxygen delivery systems across SSA and that most facilities are ill-equipped to identify adult patients with hypoxemia, provide oxygen to those who need it, and titrate or discontinue oxygen appropriately. Data are limited to mainly surveys, assessments, and observational studies, which cannot be validated, and the simple existence of an oxygen delivery system cannot be directly correlated with patient outcomes. Yet hypoxemia is still associated with significant mortality in many adult populations, and the ability to address it is limited in many care settings. Together, our findings highlight a number of important limitations and opportunities in addressing a critical health issue throughout SSA.

First, oxygen must be made more readily available and accessible at health care facilities providing care to adults, with emphasis being placed on public and lower-tier health centers. Stakeholder engagement is key to this process and needs assessments should be done to ensure facilities and communities are involved in decision-making. This will require a concerted effort by national, regional and local governments, ministries of health, policy experts, health care workers, and health facility leadership to identify the appropriate oxygen delivery system for each setting and to ensure adequate resources are available for the maintenance of these systems.

Our analysis shows that concentrators are more cost-effective than oxygen cylinders in areas where there is reliable access to power. Innovation around lowering the cost of devices and providing reservoirs during outages may be helpful, and there will need to be a significant focus on building infrastructure around reliable power. Projects in resource-limited settings outside of SSA may be helpful in this regard. For example, studies in Papua New Guinea describe the process and effectiveness of an oxygen program which included provision of pulse oximeters, training of staff and installation of oxygen concentrators, as well as the design and feasibility of a solar-powered oxygen system $[48,49]$. Similarly, trials focused on improving access to oxygen among pe- 
diatric populations in SSA, especially those exploring solar-power as an energy source, may provide the data and basic infrastructure needed to improve access for adults [50-52]. Innovations such as these are critical in facilitating oxygen availability in lower-tier health centers.

Second, health care workers need appropriate equipment, education, training, and feedback in order to use oxygen appropriately and effectively. Identifying patients who need oxygen therapy is limited by a lack of pulse oximeters and knowledge, and appropriately initiating, titrating, and discontinuing oxygen therapy is limited by a lack of knowledge and training among health care workers at all levels. Pulse oximeters should be in place at every health care facility. They are an easy-to-use and relatively affordable method of identifying patients at greatest risk of mortality. Oxygen tubing and patient delivery devices such as nasal prongs or face masks must be readily available, and a steady supply chain must be maintained. Education and training of health care workers around oxygen saturation, hypoxemia, and effective oxygen dosing can ensure that resources are being used efficiently [44].

A challenge in administering oxygen not yet addressed in this review is the oxygen saturation threshold below which oxygen should be provided in various settings and among various populations. Most included studies used an oxygen saturation below $90 \%$ as their threshold. This is reasonable for most patients with acute hypoxemia and is the threshold recommended in a WHO manual on oxygen therapy for children [53]. However, for patients with chronic hypoxemia from primary lung disease or for populations living at higher altitude where the partial pressure of oxygen is lower, a lower threshold may be more appropriate. These populations often have physiologic compensations allowing them to tolerate lower oxygen levels; providing excess oxygen may in fact cause harm. Therefore, education and training has to be contextualized for each setting and practitioners need to be capable of individualizing therapy for each patient.

Third, there were no studies assessing the prevalence of hypoxemia among outpatients and the availability of long-term oxygen therapy for home use. If we extrapolate from the severe limitations in hospital settings, we can infer this infrastructure is severely limited. In 2017, over 544 million people had a chronic respiratory disease, representing an increase of nearly 40\% since 1990 [54]. Prevalence in SSA is likely underestimated due to a lack of diagnostic capabilities, but is expected to grow as life-expectancy increases in many countries [55]. Any efforts to reduce disability or mortality from chronic respiratory disease that do not include building infrastructure for long-term oxygen therapy will fall short given what is known about its mortality and quality of life benefits $[3,4]$.

Finally, while this review was conceptualized and undertaken prior to the COVID-19 pandemic, it is impossible to ignore the disparities in resource allocation that the pandemic has underscored. Articles in the popular media have highlighted the enormous need for oxygen in countries across the world, many in SSA, as well as the incredible barriers in accessing it $[56,57]$. This enhanced awareness has facilitated increased work and innovation in this area [58]. As donations of oxygen concentrators pour in from international organizations and aid agencies, it will be important to ensure that aid extends past simple provision of these systems to maintenance, training, and local capacity building.

The major strength of our scoping review is its comprehensive scope and wide inclusion of studies addressing oxygen delivery systems in various ways. We aimed to evaluate the depth and breadth of knowledge and research on oxygen delivery systems in SSA and were able to summarize the evidence in this field. Limitations of our study include that this is not a systematic review, and therefore we cannot aim to assess the quality of articles or make definitive inferences; similarly, we cannot aim to assess the risk of bias given the descriptive nature of our objectives and the types of studies presented which were mainly surveys and observational data; by limiting our review to full-text articles, we may have missed relevant data available in abstracts; and included studies encompassed only 22 of 46 SSA countries so may not be representative of the general population or region.

In conclusion, our findings highlight the substantial need for further research and building capacity for oxygen therapy for adults across SSA and signals a call to action. We provide multiple potential action items for health care workers, researchers, policy makers, and organizations to consider as we move towards improving the care of and outcomes among patients with respiratory diseases. 


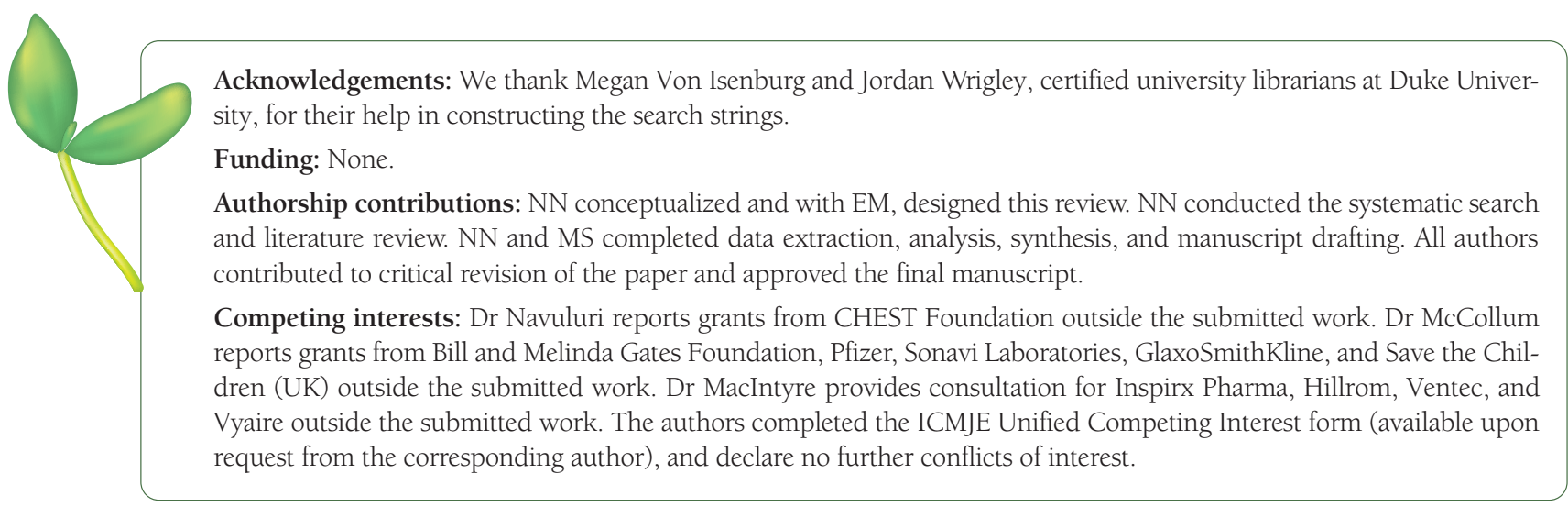

1 Societies FoIR. The Global Impact of Respiratory Disease - Second Edition. Sheffield, European Respiratory Society; 2017.

2 Heffner JE. The Story of Oxygen. Respir Care. 2013;58:18-31. Medline:23271817 doi:10.4187/respcare.01831

3 Nocturnal Oxygen Therapy Trial Group. Continuous or nocturnal oxygen therapy in hypoxemic chronic obstructive lung disease: a clinical trial. Ann Intern Med. 1980;93:391-8. Medline:6776858 doi:10.7326/0003-4819-93-3-391

4 Report of the Medical Research Council Working Party. Long term domiciliary oxygen therapy in chronic hypoxic cor pulmonale complicating chronic bronchitis and emphysema. Lancet. 1981;1:681-6. Medline:6110912

5 World Health Organization. WHO Model List of Essential Medicines. 2017. Available: https://apps.who.int/iris/bitstream/handle/10665/273826/EML-20-eng.pdf?ua=1. Accessed: 28 October 2019.

6 World Health Organization. WHO Model List of Essential Medicines. 2002. Available: https://apps.who.int/iris/bitstream/handle/10665/67335/a76618.pdf?sequence=1. Accessed: 28 October 2019.

7 Technical specifications for oxygen concentrators. Geneva: World Health Organization; 2015.

8 World Health Organization. Oxygen therapy for children. 2016. Available: https://apps.who.int/iris/bitstream/handle/10665/204584/9789241549554_eng.pdf?sequence=1. Accessed: 28 October 2019.

9 Arksey H, O’Malley L. Scoping studies: towards a methodological framework. Int J Soc Res Methodol. 2005;8:19-32. doi:10.1080/1364557032000119616

10 Levac D, Colquhoun H, O'Brien KKJI. Scoping studies: advancing the methodology. 2010;5:69.

11 Cochrane Effective Practice and Organisation of Care. Data collection form. EPOC Resources for review authors. 2017. Available: epoc.cochrane.org/epoc-resources-review-authors. Accessed: 20 April 2019.

12 Adipa FE, Aziato L, Zakariah AN. Qualitative exploration of nurses' perspectives on clinical oxygen administration in Ghana. Int J Afr Nurs Sci. 2015;2:42-6. doi:10.1016/j.ijans.2015.03.002

13 Albutt K, Punchak M, Kayima P, Namanya DB, Anderson GA, Shrime MG. Access to Safe, Timely, and Affordable Surgical Care in Uganda: A Stratified Randomized Evaluation of Nationwide Public Sector Surgical Capacity and Core Surgical Indicators. World J Surg. 2018;42:2303-13. Medline:29368021 doi:10.1007/s00268-018-4485-1

14 Albutt K, Drevin G, Yorlets RR, Svensson E, Namanya DB, Shrime MG, et al. 'We are all serving the same Ugandans': A nationwide mixed-methods evaluation of private sector surgical capacity in Uganda. PLoS One. 2019;14:e0224215. Medline:31648234 doi:10.1371/journal.pone.0224215

15 Belle J, Cohen H, Shindo N, Lim M, Velazquez-Berumen A, Ndihokubwayo JB, et al. Influenza preparedness in low-resource settings: a look at oxygen delivery in 12 African countries. J Infect Dev Ctries. 2010;4:419-24. Medline:20818088 doi:10.3855/ jidc. 859

16 Bradley BD, Chow S, Nyassi E, Cheng YL, Peel D, Howie SRC. A retrospective analysis of oxygen concentrator maintenance needs and costs in a low-resource setting: experience from The Gambia. Health Technol (Berl). 2015;4:319-28. doi:10.1007/ s12553-015-0094-2

17 Bradley BD, Light JD, Ebonyi AO, N’Jai PC, Ideh RC, Ebruke BE, et al. Implementation and 8-year follow-up of an uninterrupted oxygen supply system in a hospital in The Gambia. Int J Tuberc Lung Dis. 2016;20:1130-4. Medline:27393551 doi:10.5588/ijtld.15.0889

18 Burssa D, Teshome A, Iverson K, Ahearn O, Ashengo T, Barash D, et al. Safe Surgery for All: Early Lessons from Implementing a National Government-Driven Surgical Plan in Ethiopia. World J Surg. 2017;41:3038-45. Medline:29030677 doi:10.1007/ s00268-017-4271-5

19 Calderon R, Morgan MC, Kuiper M, Nambuya H, Wangwe N, Somoskovi A, et al. Assessment of a storage system to deliver uninterrupted therapeutic oxygen during power outages in resource-limited settings. PLoS One. 2019;14:e0211027. Medline:30726247 doi:10.1371/journal.pone.0211027

20 Desalu OO, Onyedum CC, Iseh KR, Salawu FK, Salami AK. Asthma in Nigeria: are the facilities and resources available to support internationally endorsed standards of care? Health Policy. 2011;99:250-4. Medline:21056506 doi:10.1016/j.healthpol.2010.10.006

21 Evans HT, Mahmood N, Fullerton DG, Rylance J, Gonani A, Gordon SB, et al. Oxygen saturations of medical inpatients in a Malawian hospital: cross-sectional study of oxygen supply and demand. Pneumonia. 2016;1:3-6. Nathan Qld. Medline:31463177 doi:10.15172/pneu.2012.1/208 
22 Hill SE, Njie O, Sanneh M, Jallow M, Peel D, Njie M, et al. Oxygen for treatment of severe pneumonia in The Gambia, West Africa: a situational analysis. Int J Tuberc Lung Dis. 2009;13:587-93. Medline:19383191

23 Howie SR, Hill SE, Peel D, Sanneh M, Njie M, Hill PC, et al. Beyond good intentions: lessons on equipment donation from an African hospital. Bull World Health Organ. 2008;86:52-6. Medline:18235890 doi:10.2471/BLT.07.042994

24 Howie SR, Hill S, Ebonyi A, Krishnan G, Njie O, Sanneh M, et al. Meeting oxygen needs in Africa: an options analysis from the Gambia. Bull World Health Organ. 2009;87:763-71. Medline:19876543 doi:10.2471/BLT.08.058370

25 Kouo-Ngamby M, Dissak-Delon FN, Feldhaus I, Juillard C, Stevens KA, Ekeke-Monono M. A cross-sectional survey of emergency and essential surgical care capacity among hospitals with high trauma burden in a Central African country. BMC Health Serv Res. 2015;15:478. Medline:26496762 doi:10.1186/s12913-015-1147-y

26 Kushner AL, Cherian MN, Noel L, Spiegel DA, Groth S, Etienne C. Addressing the Millennium Development Goals from a surgical perspective: essential surgery and anesthesia in 8 low- and middle-income countries. Arch Surg. 2010;145:154-9. Medline:20157083 doi:10.1001/archsurg.2009.263

27 LeBrun DG, Chackungal S, Chao TE, Knowlton LM, Linden AF, Notrica MR, et al. Prioritizing essential surgery and safe anesthesia for the Post-2015 Development Agenda: Operative capacities of 78 district hospitals in 7 low- and middle-income countries. Surgery. 2014;155:365-73. Medline:24439745 doi:10.1016/j.surg.2013.10.008

28 Nyarko KM, Ameme DK, Ocansey D, Commeh E, Markwei MT, Ohene SA. Capacity assessment of selected health care facilities for the pilot implementation of Package for Essential Non-communicable Diseases (PEN) intervention in Ghana. Pan Afr Med J. 2016;25:16. Medline:28149441 doi:10.11604/pamj.supp.2016.25.1.6252

29 Ologunde R, Vogel JP, Cherian MN, Sbaiti M, Merialdi M, Yeats J. Assessment of cesarean delivery availability in 26 lowand middle-income countries: a cross-sectional study. Am J Obstet Gynecol. 2014;211:504.e1-.e12. Medline:24844851 doi:10.1016/j.ajog.2014.05.022

30 Otiangala D, Agai NO, Olayo B, Adudans S, Ng CH, Calderon R, et al. Oxygen insecurity and mortality in resource-constrained healthcare facilities in rural Kenya. Pediatr Pulmonol. 2020;55:1043-9. Medline:32040889 doi:10.1002/ppul.24679

31 Opio MO, Nansubuga G, Kellett J. In-hospital mortality of acutely ill medical patients admitted to a resource poor hospital in sub-Saharan Africa and to a Canadian regional hospital compared using the abbreviated VitalPAC Early Warning Score. Eur J Intern Med. 2014;25:142-6. Medline:24140259 doi:10.1016/j.ejim.2013.09.013

32 Ouedraogo NS, Schimanski C. Energy poverty in healthcare facilities: a "silent barrier" to improved healthcare in sub-Saharan Africa. J Public Health Policy. 2018;39:358-71. Medline:29950575 doi:10.1057/s41271-018-0136-x

33 Penoyar T, Cohen H, Kibatala P, Magoda A, Saguti G, Noel L, et al. Emergency and surgery services of primary hospitals in the United Republic of Tanzania. BMJ Open. 2012;2:e000369. Medline:22307096 doi:10.1136/bmjopen-2011-000369

34 Rassool RP, Sobott BA, Peake DJ, Mutetire BS, Moschovis PP, Black JF. A Low-Pressure Oxygen Storage System for Oxygen Supply in Low-Resource Settings. Respir Care. 2017;62:1582-7. Medline:28951467 doi:10.4187/respcare.05532

35 Rudd KE, Tutaryebwa LK, West TE. Presentation, management, and outcomes of sepsis in adults and children admitted to a rural Ugandan hospital: A prospective observational cohort study. PLoS One. 2017;12:e0171422. Medline:28199348 doi:10.1371/journal.pone.0171422

36 Aston SJ, Ho A, Jary H, Huwa J, Mitchell T, Ibitoye S, et al. Etiology and Risk Factors for Mortality in an Adult Community-acquired Pneumonia Cohort in Malawi. Am J Respir Crit Care Med. 2019;200:359-69. Medline:30625278 doi:10.1164/ rccm.201807-13330C

37 Dickson SJ, Clay KA, Adam M, Ardley C, Bailey MS, Burns DS, et al. Enhanced case management can be delivered for patients with EVD in Africa: Experience from a UK military Ebola treatment centre in Sierra Leone. J Infect. 2018;76:383-92. Medline:29248587 doi:10.1016/j.jinf.2017.12.006

38 Foran M, Ahn R, Novik J, Tyer-Viola L, Chilufya K, Katamba K, et al. Prevalence of undiagnosed hypoxemia in adults and children in an under-resourced district hospital in Zambia. Int J Emerg Med. 2010;3:351-6. Medline:21373304 doi:10.1007/ s12245-010-0241-5

39 Hesse IF. Knowledge of asthma and its management in newly qualified doctors in Accra, Ghana. Respir Med. 1995;89:35-9. Medline:7708978 doi:10.1016/0954-6111(95)90068-3

40 Kabeza AB, Twagirumugabe T, Walker I, Shigemasa I. Incidence and risk factors of undetected postoperative hypoxaemia at a Teaching Hospital in AfricaRwanda: The usefulness of Portable oximeter. Br J Anaesth. 2012;108:ii314.

41 Mwita CC, Muthoka J, Maina S, Mulingwa P, Gwer S. Early management of traumatic brain injury in a Tertiary hospital in Central Kenya: A clinical audit. J Neurosci Rural Pract. 2016;7:97-101. Medline:26933354 doi:10.4103/0976-3147.165390

42 Sani MU, Cotter G, Davison BA, Mayosi BM, Damasceno A, Edwards C, et al. Symptoms and Signs of Heart Failure at Admission and Discharge and Outcomes in the Sub-Saharan Acute Heart Failure (THESUS-HF) Registry. J Card Fail. 2017;23:73942. Medline:27664511 doi:10.1016/j.cardfail.2016.09.016

43 Scott JW, Nyinawankusi JD, Enumah S, Maine R, Uwitonze E, Hu Y, et al. Improving prehospital trauma care in Rwanda through continuous quality improvement: an interrupted time series analysis. Injury. 2017;48:1376-81. Medline:28420542 doi:10.1016/j.injury.2017.03.050

44 Sutherland T, Moriau V, Niyonzima JM, Mueller A, Kabeja L, Twagirumugabe T, et al. The "Just Right" Amount of Oxygen. Improving Oxygen Use in a Rwandan Emergency Department. Ann Am Thorac Soc. 2019;16:1138-42. Medline:31145642 doi:10.1513/AnnalsATS.201811-763QI

45 Toure NO, Diao M, Kane A, Diop IB, Sarr M, Ba SA, et al. Chronic cor pulmonale: a study of 34 cases in the Dakar University Hospital Center Cardiology Department. Dakar Méd. 2000;45:108-12. Medline:15779162

46 Worodria W, Chang E, Andama A, Sanyu I, Byanyima P, Musisi E, et al. Predictors of Mortality Among Hospitalized Patients With Lower Respiratory Tract Infections in a High HIV Burden Setting. J Acquir Immune Defic Syndr. 2018;79:624-30. Med- 
line:30222660 doi:10.1097/QAI.0000000000001855

47 Salami TA. Exacerbators and treatment outcomes of hospitalised patients with chronic obstructive pulmonary disease (COPD) in a suburban centre in Nigeria. Am J Respir Crit Care Med. 2017;195:A1700.

48 Matai S, Peel D, Wandi F, Jonathan M, Subhi R, Duke TJA. Implementing an oxygen programme in hospitals in Papua New Guinea. Ann Trop Paediatr. 2008;28:71-8. doi:10.1179/146532808X270716

49 Duke T, Hwaihwanje I, Kaupa M, Karubi J, Panauwe D, Sa'avu M, et al. Solar powered oxygen systems in remote health centers in Papua New Guinea: a large scale implementation effectiveness trial. J Global Health. 2017;7:010411. doi:10.7189/ jogh.07.010411

50 Conradi N, Mian Q, Namasopo S, Conroy AL, Hermann LL, Olaro C, et al. Solar-powered oxygen delivery for the treatment of children with hypoxemia: protocol for a cluster-randomized stepped-wedge controlled trial in Uganda. Trials. 2019;20:679. Medline:31805985 doi:10.1186/s13063-019-3752-2

51 Hawkes MT, Conroy AL, Namasopo S, Bhargava R, Kain KC, Mian Q, et al. Solar-Powered Oxygen Delivery in Low-Resource Settings: A Randomized Clinical Noninferiority Trial. JAMA Pediatr. 2018;172:694-6. Medline:29800014 doi:10.1001/jamapediatrics. 2018.0228

52 Turnbull H, Conroy A, Opoka RO, Namasopo S, Kain KC, Hawkes M. Solar-powered oxygen delivery: proof of concept. Int J Tuberc Lung Dis. 2016;20:696-703. Medline:27084827 doi:10.5588/ijtld.15.0796

53 World Health Organization. Oxygen therapy for children: a manual for health workers. 2016.

54 GBD 2017 Disease and Injury Incidence and Prevalence Collaborators. Global, regional, and national incidence, prevalence, and years lived with disability for 354 diseases and injuries for 195 countries and territories, 1990-2017: a systematic analysis for the Global Burden of Disease Study 2017. Lancet. 2018;392:1789-858. doi:10.1016/S0140-6736(18)32279-7

55 Labaki WW, Han MK. Chronic respiratory diseases: a global view. Lancet Respir Med. 2020;8:531-3. Medline:32526184 doi:10.1016/\$2213-2600(20)30157-0

56 McNeil DGJ. A Simple Way to Save Lives as Covid-19 Hits Poorer Nations. The New York Times. 2020 2020/09/30/ T12:44:43-04:00; Sect. Health.

57 Davies MMS, Onwuzoo A. Lack of oxygen leaves patients in Africa gasping for air. The Bureau of Investigative Journalism. Available: https://www.thebureauinvestigates.com/stories/2020-08-09/lack-of-oxygen-leaves-covid-19-patients-in-africa-gasping-for-air. Accessed: 9 August 2020.

58 Canada G. Innovators mobilize to help developing countries combat Covid-19. 2020. Available: https://www.grandchallenges. ca/2020/innovators-mobilize-to-help-developing-countries-combat-covid-19/. Accessed: 15 February 2020. 